\title{
Hepatitis B: \\ Canada's overlooked sexually transmitted disease
}

\author{
J MICHAEL DIXON, MD
}

S EXUAL ACTIVITY IS AN IMPORTANT MODE OF TRANSmission of hepatitis B virus in countries with low endemic disease.

An increasing proportion of hepatitis B infections in North America are being transmitted through heterosexual contact. As a consequence more attention is now being given to heterosexual transmission of hepatitis B and how this mode of transmission can be best addressed through disease prevention and control programs.

During a one-day symposium sponsored by the Canadian Association for Clinical Microbiology and Infectious Diseases (CACMID) through an educational grant from SmithKline Beecham Pharma, an international group of epidemiologists, medical microbiologists, public health officials and communicable disease specialists met in Toronto to discuss the growing threat of hepatitis $\mathrm{B}$ as a sexually transmitted disease.

At the meeting, efforts were made to define the magnitude of heterosexually transmitted hepatitis $\mathrm{B}$ in Canada and to outline ways to control the disease both by preventing its transmission and by rendering the susceptible population immune.

A number of questions relating to hepatitis B and particularly the heterosexual aspects of the disease - were posed and discussed by the participants:

- Who is at highest risk in Canada?

- Is it possible to identify Canadians who are currently at risk or who will be at risk in the future; and what is the best estimate of the magnitude of the problem?

- Are existing policies of hepatitis B control, both national and provincial, adequately controlling viral transmission?

- Are existing epidemiological data adequate to support policy decisions regarding enhanced measures to control hepatitis B, including expansion of immunization programs?

- How can the routes of transmission be blocked; and what is the relative importance of the vaginal and anorectal routes and of virus in saliva?

- What special strategies might help in controlling the transmission of hepatitis B in adolescents?

- Should an improved information campaign that includes correction of erroneous perceptions be undertaken?

- If new control programs are necessary, by whom would they best be implemented?

- If universal vaccination is being considered. at what age should it be administered infancy or adolescence or both?

- If infancy is selected, would a 'catch-up' campaign for those aged one to 12 years be needed?

- How could an augmented vaccination program be integrated with present programs and what are the cost implications? How should the effectiveness of such a program be monitored? 


\section{RATIONALE FOR A CANADIAN CONSENSUS CONFERENCE}

It is timely to examine the issue of heterosexual transmission of hepatitis B virus in Canada.

In the United States, heterosexual activity is now reported to account for more than $25 \%$ of hepatitis B cases. Although the epidemiology of hepatitis $B$ varies from country to country, the variation being particularly noticeable between developed and developing nations, there is a pressing need to evaluate the role that heterosexual transmission is currently playing in Canada.

When the problem has been defined to the best extent that available data allow, attention must be given to measures that will either prevent viral transmission or raise the immunity of those at risk.

Controlling viral transmission is unlikely to be more successful than has been the case with etiological agents of the other sexually transmitted diseases: thus it is likely that emphasis will have to be placed on the safe and effective vaccine that is currently available.

Until now, vaccination has been used not to prevent sexually transmitted hepatitis B but rather to prevent infection in other high risk groups, especially in those which can be readily reached, such as health care workers.

For prevention of heterosexually acquired disease, a number of vaccination strategies can be considered. Most involve relatively large scale vaccination programs because of the nature of the problem and the difficulty of reaching groups believed to be at highest risk.

It is timely to consider such programs since in many parts of the world large scale or universal immunization programs against hepatitis B are being implemented or seriously considered, although not, in these instances, primarily because of heterosexually transmitted disease.

Canada's health care system, the prevalence of disease and high risk groups will differ in greater or lesser degree from those of other nations. So Canada is unique, as is every other country. It is appropriate, therefore, to examine Canadian data and the Canadian health care system to devise a policy that best suits Canada.

This is a time of great change in the fight against hepatitis $B$, and now is the proper time to re-evaluate critically the control measures currently in effect against this disease, to determine whether adjustments or improvements can bc. made.

It is appropriate to learn how other countries are meeting the challenge and the reasons for their approaches. Strategies for use of vaccines can vary widely not only between developed and developing countries as in the case of $B C G$ vaccination of infants, but also between developed countries, as with past differences in the approach to rubella by the United Kingdom compared to the United States.

The present suggestions may thus differ from those in other jurisdictions, but so they should if they are to fit Canadian circumstances.

A conference of experts from diverse specialties, all with something to offer in relation to the problem under discussion, is an ideal forum in which useful practical policy recommendations can be evolved. 


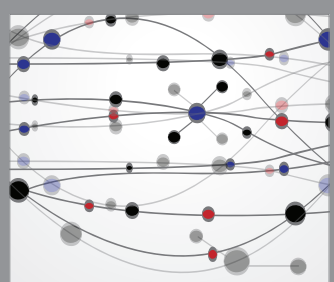

The Scientific World Journal
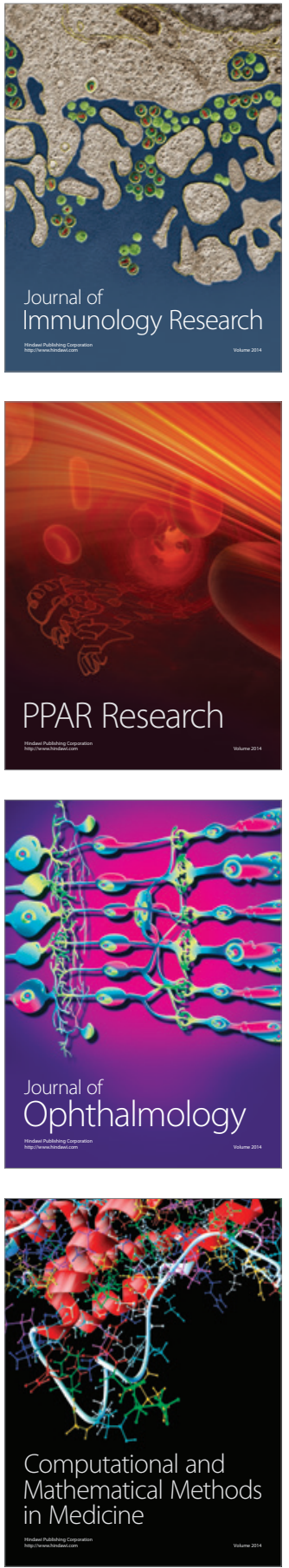

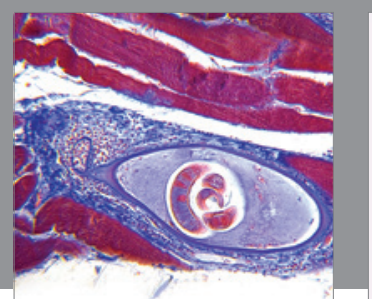

Gastroenterology Research and Practice

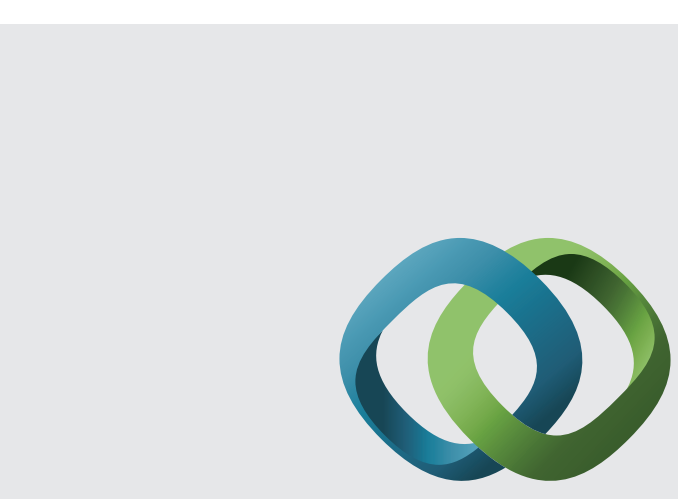

\section{Hindawi}

Submit your manuscripts at

http://www.hindawi.com
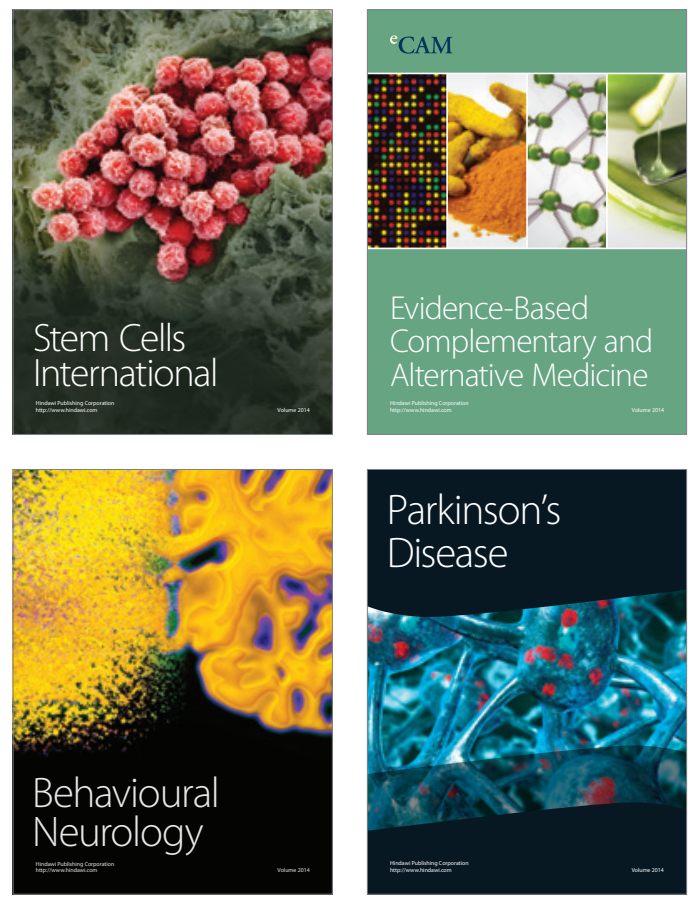
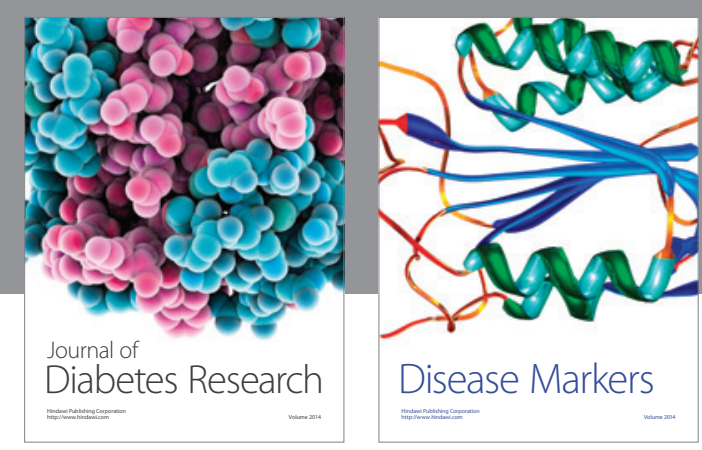

Disease Markers
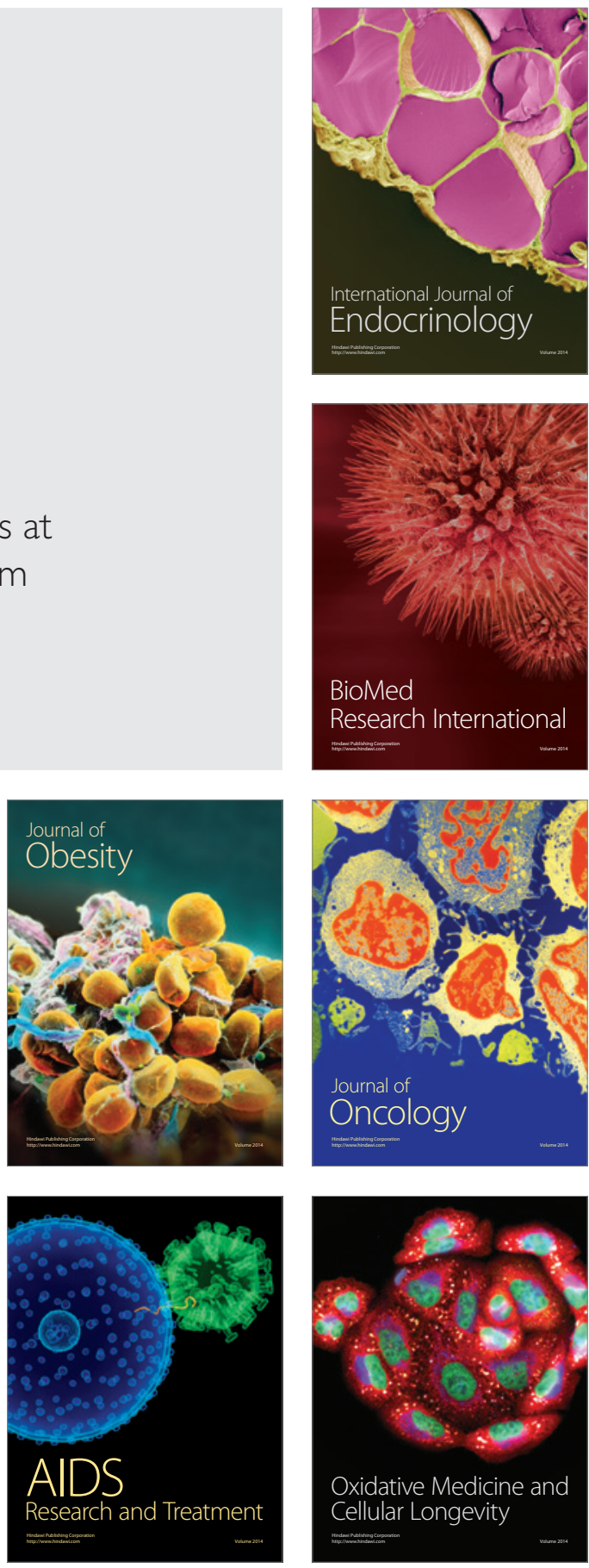